\title{
LIBERDADE DE EXPRESSÃO E SEUS LIMITES: CONTRIBUTO PARA 0 ESTUDO DO TEMA A PARTIR DE JEREMY WALDRON
}

\author{
FREEDOM OF SPEECH AND ITS LIMITS: CONTRIBUCTION TO THE STUDY OF \\ THE SUBJECT FROM JEREMY WALDRON
}

\author{
LIBERTAD DE EXPRESIÓN Y SUS LÍMITES: CONTRIBUCIÓN AL ESTUDIO \\ DEL TEMA DESDE JEREMY WALDRON
}

\author{
MARTHA TORIBIO LEÃO \\ http://orcid.org/0000-0003-3300-6591 / http:// lattes.cnpq.br/5079020283798345 / marthatleao@gmail.com \\ Universidade Presbiteriana Mackenzie \\ São Paulo, SP, Brasil
}

\begin{abstract}
RESUMO
O objetivo deste artigo é analisar criticamente a teoria de Jeremy Waldron sobre a liberdade de expressão e a regulação do discurso de ódio. Para tanto, o artigo está dividido em três partes. Na primeira parte, analisa-se a teoria de Jeremy Waldron sobre liberdade de expressão a partir do exame dos seus três pilares (dignidade, sense of assurance e vulnerabilidade), e demonstra-se que a teoria de Waldron permite o sopesamento dos princípios especialmente em virtude das consequências produzidas pelo discurso. Na segunda parte, são apresentadas as principais críticas formuladas por Edwin C. Baker e Ronald Dworkin à teoria de Jeremy Waldron, bem como as respectivas respostas. Na terceira parte, defende-se a crítica formulada por Ronald Dworkin à teoria de liberdade de expressão de Jeremy Waldron, no sentido de que essa permite a restrição da liberdade de expressão ainda quando isso represente uma violação a um direito individual. 0 artigo conclui que a tese de Waldron falha em criar critérios objetivamente controláveis para definir as hipóteses nas quais o discurso de ódio deve ser proibido ou regulado.
\end{abstract}

Palavras-chave: Discurso de ódio; Liberdade de expressão; Sopesamento de princípios.

\section{ABSTRACT}

The aim of this article is to critically analyze Jeremy Waldron's theory on freedom of expression and regulation of hate speech. In order to do so, the article is divided in three parts. In the first part, Jeremy Waldron's theory on freedom of speech is analyzed through the examination of its three cornerstones (dignity, sense of assurance and vulnerability) and it is shown that Waldron's theory allows for the balancing of principles especially in virtue of the consequences produced by the speech. In the second part, the main critics formulated by Edwin C. Baker and Ronald Dworkin against Jeremy Waldron's theory are presented, as well as their respective answers. In the third part, the critic formulated by Ronald Dworkin against Jeremy Waldron's theory, in the sense that it allows for the restriction of free speech even when this represents a violation of individual rights, is defended. The article concludes that Waldron's thesis fails in creating objective controllable criteria to define the hypothesis in which hate speech must be prohibited or regulated.

Keywords: Hate speech; Freedom of expression; Balancing of principles.

\section{RESUMEN}

El objetivo de este artículo es analizar críticamente la teoría de Jeremy Waldron sobre la libertad de expresión y la regulación del discurso de odio. Para ello, el artículo se divide en tres partes. En la primera parte, la teoría de Jeremy Waldron sobre la libertad de expresión se analiza a través del examen de sus tres pilares (dignidad, sentido de seguridad y vulnerabilidad) y se muestra que la teoría de Waldron permite el equilibrio de principios, especialmente en virtud de las consecuencias producidas. por el discurso. En la segunda parte, se presentan los principales críticos formulados por Edwin C. Baker y Ronald Dworkin contra la teoría de Jeremy Waldron, así como sus respectivas respuestas. En la tercera parte, se defiende la crítica formulada por Ronald Dworkin contra la teoría de Jeremy Waldron, en el sentido de que permite la restricción de la libertad de expresión, incluso cuando esto representa una 
violación de los derechos individuales. El artículo concluye que la tesis de Waldron falla al crear criterios objetivos controlables para definir la hipótesis en la que se debe prohibir o regular el discurso de odio.

Palabras clave: El discurso del odio; Libertad de expresión; Equilibrio de principios.

\section{SUMÁRIO}

INTRODUÇÃO; 1 WALDRON E A LIBERDADE DE EXPRESSÃO: DIGNIDADE, SENSE OF ASSURANCE E VULNERABILIDADE; 2 BAKER E A AUTONOMIA FORMAL E WALDRON E OS DANOS; 3 DWORKIN E 0 ARGUMENTO DE PRINCÍPIO E WALDRON E O ARGUMENTO CONSEQUENCIALISTA; CONCLUSÃO; REFERÊNCIAS.

\section{INTRODUÇÃO}

O tema da liberdade de expressão nunca foi tão atual. Discussões acerca dos limites da liberdade de expressão, especialmente em um cenário de crise política e de fake news, tornamse cada vez mais prementes no Direito brasileiro. Nesse contexto, a análise de teorias clássicas sobre a matéria pode ajudar na reflexão acerca do significado do princípio da liberdade de expressão e na existência e validade da imposição de limites a essa liberdade. Este artigo se propõe a contribuir para esse debate a partir de uma resenha da posição doutrinária de Jeremy Waldron, cuja teoria foi determinante para o desenvolvimento do conceito de liberdade de expressão nos Estados Unidos - país no qual o debate sobre esse tema mostra-se mais avançado pelo elevado número de casos judiciais em que essa matéria foi abordada. Assim, a pesquisa bibliográfica sobre a posição do autor, dos seus críticos principais e as suas respostas a esses críticos permite avançar na reflexão sobre esse conceito, contribuindo para o seu desenvolvimento também no ordenamento jurídico brasileiro.

Jeremy Waldron é um dos principais defensores da regulação do discurso de ódio, tendo apresentado uma série de argumentos e de contra-argumentos aos seus críticos na defesa de sua tese. Nesta resenha, analisaremos, em primeiro lugar, a estrutura geral do pensamento de Waldron sobre a liberdade de expressão e a regulação do discurso de ódio, a partir da obra “The Harm in Hate Speech". ${ }^{1}$ Em segundo lugar, apresentaremos duas das principais e mais convincentes críticas dirigidas à sua tese, respectivamente, de Baker e Dworkin, bem como os contra-argumentos de Waldron a essas críticas, que foram respondidas em capítulos específicos de sua obra. E, em terceiro lugar, após estabelecidas essas premissas doutrinárias, nos posicionaremos sobre o debate, apresentando os argumentos teóricos que levam à concordância

\footnotetext{
${ }^{1}$ WALDRON, Jeremy. The Harm in Hate Speech. Cambridge: Harvard University Press, 2012.
} 
com o posicionamento de Dworkin, e, consequentemente à crítica à tese de Waldron e sua argumentação consequencialista sobre a liberdade de expressão, baseada na proporcionalidade.

\section{WALDRON E A LIBERDADE DE EXPRESSÃO: DIGNIDADE, SENSE OF ASSURANCE E VULNERABILIDADE}

A liberdade de expressão em Waldron está fundamentada em três pilares: dignidade, sense of assurance e vulnerabilidade. Esses pilares, no entanto, não são apresentados de forma conjunta pelo desenvolvimento da teoria do autor, mas vão sendo somados na medida em que ele procura contra-argumentos às teses críticas à sua. Passamos a analisá-los um a um.

Em primeiro lugar, a tese de Waldron sobre a liberdade de expressão está baseada na ideia de dignidade. A dignidade, em Waldron, não tem o conceito que usualmente the é atribuído pela doutrina ou pela jurisprudência. O conceito de dignidade utilizado pelo autor é vinculado à posição social do indivíduo, ou seja, à ideia de homem-político. A dignidade, nessa linha, não está vinculada à honra ou à estima, mas ao "direito básico de ser lembrado, enquanto membro de uma sociedade, em uma condição favorável, alguém cujo pertencimento a um grupo minoritário não o desqualifica na interação social ordinária”.2

0 entendimento de Waldron transforma a dignidade em uma acepção social, que é maior do que a sua acepção individual. Por dignidade, ele se refere ao status do indivíduo enquanto alguém dotado de igualdade de tratamento na comunidade em que habita, no tocante ao seu direito de acesso à justiça básica e à sua reputação. Nesse ponto, Koppelman, analisando o discurso de Waldron, apontou semelhanças entre ele e os discursos de Mill e Milton, especialmente em virtude do reconhecimento da liberdade de expressão como um direitoresponsabilidade. Esta noção está vinculada à ideia de que a função da sociedade é permitir a autorrealização do indivíduo e seu florescimento. Por essa razão, haveria compatibilidade entre as teses de Mill e Milton e a tese de Waldron, isto é, ainda que não sejam idênticas, a tese de Waldron se mostraria compatível com esta premissa adotada por Mill e Milton. 0 limite ao discurso, para todos eles, estaria vinculado ao discurso que comprometesse a própria possibilidade do discurso. ${ }^{3}$

\footnotetext{
${ }^{2}$ WALDRON, Jeremy. The Harm in Hate Speech. Cambridge: Harvard University Press, 2012. p. 105.

${ }^{3}$ KOPPELMAN, Andrew. Waldron, Responsibility-rights, and Hate Speech. 43 Arizona State Law Journal 1201 (2011).
} 
Em suma, a dimensão de dignidade em Waldron não é subjetiva e individual, porque ela tem uma objetividade sociológica: a ofensa ao status (ou à dignidade) independe do sentimento, o que traz objetividade à matéria. Essa dignidade ou status é um bem público na tese de Waldron, assim como é o meio ambiente saudável. E os cidadãos têm direito a este bem público, como deixa clara a teoria política do autor. Daí a sua conclusão no sentido de que deve haver regulação ao discurso de ódio, porque este polui o meio ambiente público ao qual temos direito.

Em segundo lugar, a tese de Waldron sobre a liberdade de expressão está baseada na ideia de sense of assurance, enquanto garantia que se tem acerca da preservação de seu status na sociedade. ${ }^{4}$ Ao reconhecer a dificuldade de se lidar com um tema tão vago e impreciso como a dignidade, Waldron aponta a necessidade de se concentrar o debate da liberdade de expressão no argumento sobre a reputação, o status, a colocação da vítima na sociedade, e como o discurso de ódio pode prejudicar estas questões. ${ }^{5}$

A ideia de sense of assurance não é claramente definida pelo autor como um dado objetivo ou subjetivo. De um lado, é um dado objetivo, porque vinculado ao risco de perda do status político na sociedade. De outro lado, é um dado subjetivo, porque vinculado ao sentimento de ameaça ou insegurança. O texto oscila entre estas duas vertentes acerca do critério de sense of assurance. 0 importante, porém, é perceber que a ideia de assurance está vinculada à percepção do cidadão sobre o seu status social.

E, em terceiro lugar, a tese de Waldron sobre a liberdade de expressão está baseada na ideia de vulnerabilidade. O discurso de ódio só poderia ser considerado como tal quando atingisse grupos minoritários vulneráveis. Embora não haja um conceito preciso sobre esta vulnerabilidade, trata-se de um dado sociológico, segundo o autor. Nesse sentido, ele é claro ao afirmar que a sua tese tem como preocupação central a proteção da dignidade de indivíduos vulneráveis pertencentes a grupos minoritários, que seriam "grupos que têm atraído a raiva e o desprezo de seus concidadãos no passado". ${ }^{6}$

Esta caracterização, portanto, é contextual e depende de dados empíricos e características próprias de cada grupo em uma determinada sociedade. Tal critério, de algum modo, vincula-se à ideia de sense of assurance, porque se o cidadão pertence a maioria, não poderia ter seu status social em perigo.

\footnotetext{
${ }^{4}$ Nas palavras do autor: “(...) religious freedom means nothing if it does not mean that those others are to be recognized nevertheless as fellow citizens and secured in that status, if need be, by laws that prohibit mobilization of social forces to exclude them." (WALDRON, Jeremy. The Harm in Hate Speech. Cambridge: Harvard University Press, 2012. p. 138).

${ }^{5}$ WALDRON, Jeremy. The Harm in Hate Speech. Cambridge: Harvard University Press, 2012. p. 139.

${ }^{6}$ WALDRON, Jeremy. The Harm in Hate Speech. Cambridge: Harvard University Press, 2012. p. 123.
} 
Os três critérios anteriores demonstram que a liberdade de expressão e a regulação do discurso de ódio em Waldron misturam elementos objetivos e subjetivos, adicionados principalmente em virtude da tentativa de responder às teses opostas à sua. Adiante, verificaremos com mais afinco estas questões.

Nesse momento, contudo, basta demonstrar que a tese de Waldron finca-se em uma questão de grau, que permite o sopesamento dos princípios envolvidos, especialmente em virtude das consequências produzidas pelo discurso. Waldron, portanto, é um defensor da ponderação como forma de aplicação da liberdade de expressão através de uma análise de consequências e de eficiência. As críticas dirigidas a essa tese são muitas e, pelo menos duas delas, merecem análise pormenorizada.

\section{BAKER E A AUTONOMIA FORMAL E WALDRON E OS DANOS}

A tese da liberdade de expressão em Baker tem como argumento central a autonomia formal dos cidadãos. ${ }^{7}$ Segundo o autor, não se pode partir da premissa de que as pessoas podem fazer escolhas sozinhas e, ao mesmo tempo, aceitar que a lei limite esta autonomia. A autonomia formal envolve a livre determinação da forma de viver a sua vida (sem que esteja associada a qualquer outro valor) e sem que o Estado possa interferir na escolha do tipo de vida que cada cidadão quer levar. A democracia, para Baker, é a única ordem política que engloba um princípio normativo de respeito à autodeterminação. Em outras palavras, a democracia é a única forma de governo que respeita as pessoas como livres e iguais na tomada de decisões.

Analisando os argumentos centrais de Waldron e Baker é possível dizer que estes se aproximam com relação à instrumentalidade da liberdade de expressão. A democracia e a liberdade de expressão, para Baker, são instrumentos para a garantia dos valores da autonomia e da igualdade. De forma semelhante, a ideia de liberdade de expressão como um direitoresponsabilidade em Waldron tem um caráter instrumental vinculado à realização pessoal e a construção de uma sociedade com um meio ambiente propício ao seu desenvolvimento.

Assim, ambos os autores (Waldron e Baker) partem de concepções iniciais que podem ser assemelhadas: a liberdade de expressão, para os dois, é um direito instrumental para a realização de outros fins. Nada obstante essa concepção similar sobre a liberdade de expressão, os dois autores alcançam conclusões bastante distintas no que se refere à regulação e limitação

7 BAKER, C. Edwin. Autonomy and Hate Speech. In: HARE, Ivan; WEINSTEIN, James. (Ed.) Extreme Speech and Democracy. Oxford: Oxford University Press, 2008. p. 139-157. 
dessa liberdade. Enquanto Baker é um defensor da liberdade de expressão e contrário à proibição do discurso de ódio (e a uma regulação ampla deste), Waldron é um defensor dessa regulação de modo amplo.

A crítica existente na tese de Baker à postura de Waldron se refere à possibilidade de que o Estado interfira nas escolhas dos cidadãos de como querem viver as suas vidas. Para ele, regular o discurso de ódio significaria conceder ao Estado o direito de definir a visão de mundo que seria aceita, infringindo o direito do falante de expressar seus valores através do discurso independentemente de serem valores racistas ou homofóbicos, por exemplo. Não caberia ao Estado controlar o conteúdo do discurso, porque isso afrontaria frontalmente a autonomia formal dos cidadãos.

A tese de Baker parte de duas premissas fundamentais. A primeira premissa é que a legitimidade do Estado depende do seu respeito à igualdade e à autonomia das pessoas. $\mathrm{E}$ a segunda premissa é que o Estado só respeita, de fato, a autonomia das pessoas se permite que elas expressem os seus próprios valores independentemente de que valores sejam esses, dos danos causados a outras pessoas e das dificuldades que isso traga ao próprio Estado. ${ }^{8}$ Isso não significa que Baker negue a existência de danos. Pelo contrário, o autor aceita que esses danos de fato existem, e que as consequências importam. Seu argumento, porém, é que esses danos não justificam a regulação do discurso de ódio. ${ }^{9}$

O contra-argumento de Waldron a essa crítica segue a linha consequencialista já mencionada. ${ }^{10}$ Para o autor, a regulação do discurso baseada em seu conteúdo está relacionada com a apreensão do Estado com relação às consequências geradas pelo discurso. A legislação do discurso de ódio, e até por vezes a sua proibição, estaria vinculada à garantia de que membros de grupos vulneráveis não tenham seu status social atingido. As restrições ou proibições a esse tipo de discurso teriam exatamente a função de proteger o conjunto de bens públicos de ser minado, na medida em que o Estado teria o dever de se preocupar com o efeito do discurso na vida das pessoas.

Embora reconheça a força argumentativa da tese de Baker - qualificando-a como a melhor defesa da liberdade de expressão -, Waldron afirma que as consequências danosas da expressão não evaporam diante da argumentação de Baker. Isso significa que o discurso de ódio ainda geraria danos à dignidade e à reputação de indivíduos de grupos vulneráveis, minando,

\footnotetext{
${ }^{8}$ BAKER, C. Edwin. Autonomy and Hate Speech. In: HARE, Ivan; WEINSTEIN, James. (Ed.) Extreme Speech and Democracy. Oxford: Oxford University Press, 2008. p. 139-157 (142).

${ }^{9}$ BAKER, C. Edwin. Harm, Liberty, and Free Speech. Southern California Law Review 70 (1997). p. 986.

${ }^{10}$ WALDRON, Jeremy. The Harm in Hate Speech. Cambridge: Harvard University Press, 2012. p. 161 e ss.
} 
desse modo, o bem público. Seria preciso, portanto, sopesar esses danos com a importância da apresentação autônoma de valores pelo falante, porque esses atos não seriam puramente expressivos, porque também machucariam, aterrorizariam, desencorajariam e assustariam. Nesse sentido, o Estado não poderia tolerá-los.

\section{DWORKIN E O ARGUMENTO DE PRINCÍPIO E WALDRON E O ARGUMENTO CONSEQUENCIALISTA}

Além de Baker, a tese de Waldron também recebeu críticas de Dworkin. Segundo Dworkin, impedir que determinados discursos possam ser feitos na arena pública significaria afastar da discussão determinados falantes, o que comprometeria a legitimidade democrática das legislações sobre este tema, já que uma parte dos cidadãos não poderia participar de sua deliberação. Para o autor, "a liberdade de expressão é uma condição de legitimidade do governo. Leis e políticas não são legítimas a menos que elas tenham sido adotadas perante um processo democrático, e um processo não é democrático se o governo tiver impedido alguém de expressar suas convicções sobre como estas leis e políticas deveriam ser". ${ }^{11}$ Embora em sua obra sobre o tema Waldron dirija um capítulo específico para examinar a tese de Dworkin de um ponto de vista crítico e apresentar contra-argumentos a ela, não nos parece que o argumento escolhido para ser enfrentado tenha sido o melhor argumento de Dworkin contra a tese ali apresentada.

Com efeito, Waldron escolhe tratar da questão da perda da legitimidade democrática analisada por Dworkin em alguns artigos, inclusive de jornal. ${ }^{12}$ A essa crítica, Waldron responde no sentido de que a legitimidade seria uma questão de grau, e, que isso explicaria por que a Alemanha e a Inglaterra ainda seriam democracias, mesmo diante das críticas de Dworkin sobre as leis de regulação do discurso de ódio, como a proibição de negação do Holocausto, por exemplo.

\footnotetext{
11 DWORKIN, Ronald. Even bigots and Holocaust deniers must have their say: The British media were right not to publish the Danish cartoons, but that doesn't mean freedom of speech should have limits. The Guardian (14 $\quad$ Feb. 2006). Disponível https://www.theguardian.com/world/2006/feb/14/muhammadcartoons.comment Acesso em: 12 ago. 2021.

12 DWORKIN, Ronald. Foreword. In: HARE, Ivan; WEINSTEIN, James. (Ed.) Extreme Speech and Democracy. Oxford: Oxford University Press, 2008. p. v-ix; DWORKIN, Ronald. A New Map of Censorship. Index on Censorship 35 (2006). p. 130; DWORKIN, Ronald. Uses and abuses. 2002 Index on Censorship. p. 58-59.
} 
Em que pese a escolha de Waldron, a questão da legitimidade democrática era uma questão secundária para Dworkin e não deveria ser apresentada como a melhor crítica à teoria de Waldron. A questão mais importante em Dworkin e que serve de contraponto profundo à tese de Waldron se refere à liberdade de expressão como um direito que deve ser entendido como um trunfo para cada cidadão e, nesse sentido, se sobreporia a análises consequencialistas.

Para Dworkin, direitos individuais constrangem o Estado com relação aos instrumentos para perseguir os interesses coletivos. Isso significa que o Estado deve respeitar esses direitos mesmo quando eles contrariam aquilo que o governo entende como o bem-estar coletivo. ${ }^{13}$

Em outras palavras, alguns direitos são tão básicos e importantes que deveriam ser imunes a argumentos consequencialistas. Isso significa dizer que independentemente de as consequências geradas serem boas ou desejadas, elas não poderiam ser sopesadas diante, por exemplo, do direito de levar um tipo de vida que é essencial para cada cidadão. 0 direito da pessoa de fazer escolhas individuais nesse sentido seria um trunfo que funcionaria como uma barreira a análises consequencialistas ou utilitaristas. Esta é a estratégia de direitos do Dworkin, segundo a qual "as pessoas devem ter uma esfera privada, mesmo que isso prejudique, em vez de promover, os objetivos a longo prazo da sociedade, e, portanto, conceda à maioria das pessoas menos controle efetivo sobre o planejamento de seu ambiente". ${ }^{14}$

Para ser um direito genuíno, dentro da tese de Dworkin, o direito à independência moral exigiria uma atitude permissiva mesmo com aqueles comportamentos que não produzissem um bem em geral para a comunidade, como a pornografia. Isso porque, diante de um direito moral, o Estado não poderia atuar em violação a esse direito, ainda que acreditasse que a comunidade como um todo estaria em melhores condições se o fizesse. Dworkin, inclusive, não nega este dado, apenas refuta a ideia de que uma teoria utilitarista poderia justificar este tipo de violação de direito. ${ }^{15}$

Assim, ainda que seja uma questão de grau, o que importaria verificar nos países que regulam e até proíbem o discurso de ódio é que esse comportamento violaria o direito dos falantes. Do fato de isso ser feito não decorreria que isso é o correto. É preciso distinguir o mundo do ser do mundo do dever-ser. De fato, a Alemanha, por exemplo, proíbe o discurso de

\footnotetext{
${ }^{13}$ DWORKIN, Ronald. Taking Rights Seriously. Cambridge: Harvard University Press, 1977. p. 198.

14 DWORKIN, Ronald. Uma questão de princípio. Tradução de Luís Carlos Borges. São Paulo: Martins Fontes, 2001. p. 520.

15 "O direito à independência moral é parte da mesma coleção que o direito de independência política e deve ser justificado como trunfo sobre uma defesa utilitarista irrestrita de leis proibitivas da pornografia (...)". DWORKIN, Ronald. Uma questão de princípio. Tradução de Luís Carlos Borges. São Paulo: Martins Fontes, 2001. p. 533-534, 543.
} 
negação do holocausto. Ao fazê-lo, contudo, o país violaria a liberdade de expressão dos cidadãos que acreditam nisso e que gostariam de expressar suas convicções.

Portanto, a questão principal aqui não seria o déficit sociológico (apesar de esse ser mais um argumento nesse sentido), mas sim o argumento normativo: seria errado por princípio desconsiderar o direito de falar. E isso, para Dworkin, não poderia ser sopesado, como pretende Waldron ao tratar da questão de legitimidade. Restringir o direito de expressão - ainda que em uma análise de efeitos e consequências traga vantagens para uma determinada sociedade - seria errado por princípio, do ponto de vista da teoria da justiça apresentada por Dworkin.

Ao tratar sobre o tema, Dworkin propõe a distinção entre argumentos de política e argumentos de princípio. Por um lado, nos argumentos de política sobre a liberdade de expressão, essa seria vista apenas como um instrumento para garantir o bem-estar da comunidade, o que levaria à necessidade constante de ponderação do interesse público em qualquer tipo de decisão sobre exceções ou privilégios dessa liberdade. Por outro lado, nos argumentos de princípio, o bem-estar da comunidade seria desconsiderado diante da posição especial daquele que fala, "mesmo que a comunidade como um todo possa sofrer por permitir que ele fale". ${ }^{16}$

Dworkin defende, portanto, um argumento de princípio: os direitos morais não poderiam estar sujeitos ao sopesamento de consequências e efeitos. Eles se sobreporiam a esse tipo de análise. Essas categorias são conceituais. Por isso, Dworkin apresenta uma forte crítica ao argumento de Waldron a favor do sopesamento, acrescentando ainda que ele não ofereceria critérios intersubjetivamente controláveis para distinguir quando deveria haver regulação ou proibição: afinal, tudo deveria ser ponderado.

O contra-argumento de Waldron a essa teoria segue a linha já destacada quando do seu contra-argumento à Baker. Sua visão de liberdade de expressão como direito-responsabilidade traz uma concepção instrumental desse direito e que teria como limite o discurso que inviabiliza a própria arena pública dos discursos, tendo como método de análise a ponderação da restrição ao direito de se expressar e dos danos e consequências geradas por esse discurso àqueles que são atingidos por ele. Neste aspecto, Waldron segue a linha de uma concepção utilitarista da liberdade de expressão, parecida com a visão de Mill, no sentido de que a concepção desses

16 DWORKIN, Ronald. Uma questão de princípio. Tradução de Luís Carlos Borges. São Paulo: Martins Fontes, 2001. p. 576. 
direitos individuais derivaria exatamente do interesse coletivo desses direitos, e, exatamente por isso, deveria ser analisado perante essa finalidade. ${ }^{17}$

Referida premissa leva à possibilidade de que a liberdade de expressão seja restringida ainda que isso fira um direito individual. Waldron não reconhece que esse direitoresponsabilidade gere um direito individual que, pelo menos em alguma medida, precisaria superar suas próprias consequências. A resposta de Waldron é na mesma linha daquela sugerida por ele para enfrentar a questão da perda de legitimidade democrática: essas restrições ao direito individual de falar devem ser sopesadas com as consequências do discurso em um método de ponderação desses direitos. O juiz acaba devendo fazer um juízo de gravidade, que misturaria uma série de elementos (subjetivos e objetivos) frente ao direito de se expressar.

Waldron tenta ainda responder às críticas de Dworkin a partir de um dado empírico, de que os países europeus, de fato, regulam e restringem o discurso de ódio, e que isso não comprometeria as suas democracias. Ele, portanto, tenta extrair um argumento normativo de um dado empírico. O problema é que da premissa de que países europeus de fato regulam e restringem o discurso não se deduz a consequência de que isso é correto e não restringe o direito individual dos falantes. Não é possível extrair normas de fatos, como ensina a lei de Hume (ou guilhotina: “Hume's guillotine”): não se pode deduzir como as coisas deveriam ser a partir de como elas são. Isso significa dizer que a ordem normativa não decorre da situação fática. ${ }^{18}$

Há, portanto, um vício argumentativo nessa tese, na medida em que os argumentos só são considerados suficientes se suas premissas, tomadas em conjunto, geram prova bastante para apoiar determinada conclusão. Um argumento só é justificado se suportado por outro com o qual, naturalmente, seja compatível. ${ }^{19}$ Quando isso não ocorre, surge o vício da incompatibilidade da conclusão com a premissa. É exatamente isso que se verifica na argumentação de Waldron, porque a premissa que supostamente sustentaria a conclusão alcançada mostra-se, na realidade, incompatível com ela: da existência de regulação em países europeus não decorre a correção desta regulação ou a inexistência de violação a direitos. Não se pode, afinal, retirar um caráter normativo de um dado empírico.

17 GEORGE, Robert P. Making Men Moral - Civil liberties and public morality. Oxford: Oxford University Press, 2002, p. 83.

${ }^{18}$ AARNIO, Aulis. Introduction. In: PECZENIK, Aleksander. On Law and Reason. 2. ed. Dordrecht: Springer, 2008, p. 1-12 (8).

${ }^{19}$ DAMER, Edward. Attacking Faulty Reasoning. 6. ed. Belmont: Wadsworth, 1998, p. 72. 


\section{CONCLUSÃO}

As considerações anteriores demonstram que a tese de Waldron falha ao tentar criar critérios objetivamente controláveis para definir em quais hipóteses o discurso de ódio deveria ser proibido ou, ao menos, regulado. Embora se possa argumentar que a sua intenção não era construir uma teoria sobre a liberdade de expressão, o fato é que sua obra apresenta argumentos sobre a construção desse direito e até mesmo sobre porque a censura deveria ser criticada.

Nesse sentido, Koppelman destaca que a tese de Waldron traz tanto argumentos a favor da regulação da liberdade de expressão, como argumentos contrários a ela. ${ }^{20}$ Isso significa dizer que os próprios fundamentos apresentados por Waldron para defender a sua concepção acerca da liberdade de expressão podem levar às críticas das próprias regulações por ele defendidas. A sua tese, portanto, falha em construir um discurso coerente sobre o tema, que reforce as suas próprias conclusões. Sua tese, além disso, vai sendo enfraquecida na medida em que ele vai tentando responder aos seus críticos e, para isso, agrega novos critérios à sua própria concepção de liberdade de expressão e discurso de ódio.

O que incialmente era um problema de conteúdo vinculado à violação à dignidade, mais tarde se transforma também em um problema formal e material, a partir da inclusão da noção de sense of assurance e vulnerabilidade. No fim, a questão se transforma em um juízo de gravidade sobre o discurso, que necessariamente precisaria de ponderação para ser resolvido. Mas aqui entra a própria crítica de Post, ao defender a liberdade de expressão e criticar as regulações do discurso de ódio: no fim, estas acabam se tornando um padrão de civilidade imposto por aqueles que estão no poder e que garantem liberdade de expressão apenas àqueles que se expressam dentro deste padrão. ${ }^{21}$

Por essas razões, o discurso de Dworkin demonstra uma maior coerência e persuasão do ponto de vista teórico. Os direitos, para serem reconhecidos como tal, precisam superar as próprias consequências do seu exercício, pelo menos em grande medida. A consideração do direito à liberdade de expressão não pode ser associada e justificada por considerações acerca

${ }^{20}$ KOPPELMAN, Andrew. Waldron, Responsibility-rights, and Hate Speech, 43 Arizona State Law Journal 1201 (2011).

${ }^{21}$ POST, Robert. Hate Speech. In: HARE, Ivan; WEINSTEIN, James. (Ed.) Extreme Speech and Democracy. Oxford: Oxford University Press, 2008, p. 123-138 (131). 
do que faz a sociedade um lugar melhor. Pelo contrário, esse tipo de direito moral existe e deve ser respeitado mesmo quando seu exercício fizer com que a sociedade seja um lugar pior. ${ }^{22}$

Esta caracterização da liberdade de expressão como um trunfo tem a finalidade de criticar a metodologia do Direito pensada em termos de ponderação. Os defensores desse tipo de estrutura, como Grimm, argumentam que a ponderação nos casos de liberdade de expressão impõe a resposta a três perguntas hipotéticas: (1) qual seria a perda da liberdade de expressão se os interesses protegidos por uma determinada lei de restrição prevalecerem? (2) qual seria a perda nesses interesses se a liberdade de expressão prevalecer? e (3) qual perda tem um peso maior? ${ }^{23}$

Embora esse teste tenha sido apresentado em um texto sobre a negação do Holocausto, ele poderia ser universalizado para qualquer situação de liberdade de expressão em conflito com outros direitos. Para Grimm, assim como para Waldron, a liberdade de expressão estaria sujeita a esse tipo de ponderação que levaria em consideração as suas consequências para um sopesamento de vantagens e desvantagens, que dependeria sempre do caso concreto.

Por outro lado, o posicionamento de Dworkin tem como objetivo demonstrar porque a liberdade de expressão não pode ser submetida a esse tipo de metodologia para ser considerada como um direito. Em regra geral, para isso, ela precisa estar acima de avaliações consequencialistas, tal qual uma regra precisa estar, em grande medida, acima de ponderações de sua finalidade para ser considerada como tal. Para o autor, os direitos individuais constrangem o Estado com relação aos instrumentos para perseguir os interesses coletivos. Isso significa que o Estado deve respeitar esses direitos mesmo quando eles contrariam aquilo que o governo entende como o bem-estar coletivo. ${ }^{24}$

Tal caracterização é importante na medida em que esses direitos, para o autor, não podem estar sujeitos a sopesamento de consequências e efeitos. Seriam categorias conceituais, que se sobrepõem a este tipo de análise. Daí a crítica à ideia de ponderação no âmbito deste tipo de liberdade e, principalmente, de falta de critérios para que isso seja realizado. Os direitos, para serem reconhecidos como tais, precisariam superar as próprias consequências do seu exercício, pelo menos em grande medida. Reitera-se: para Dworkin, a consideração do

\footnotetext{
22 GEORGE, Robert P. Making Men Moral - Civil liberties and public morality. Oxford: Oxford University Press, 2002, p. 83-84.

${ }^{23}$ GRIMM, Dieter. The Holocaust Denial Decision of the Federal Constitutional Court of Germany. In: HARE, Ivan; WEINSTEIN, James. (Ed.) Extreme Speech and Democracy. Oxford: Oxford University Press, 2008, p. 557-561 (560).

${ }^{24}$ DWORKIN, Ronald. Taking Rights Seriously. Cambridge: Harvard University Press, 1977, p. 198.
} 
direito à liberdade de expressão não poderia ser associada e justificada por considerações acerca do que faz a sociedade um lugar melhor.

Pelo contrário, esse tipo de direito moral existe e deve ser respeitado mesmo quando seu exercício fizer com que a sociedade seja um lugar pior. ${ }^{25}$ Isso, significa, em outras palavras, que o Estado não pode supor que o interesse da coletividade é, sempre, em todo e qualquer caso, mais importante do que a realização de direitos fundamentais individuais. Pelo contrário, uma das principais funções dos direitos fundamentais é justamente a de proteger o indivíduo contra a imposição irresistível e absoluta de uma determinada noção de bem comum. ${ }^{26}$

Ainda que isso possa ser afastado em casos dramáticos, a regra deve ser a superação das consequências em virtude da existência desse direito individual. 0 que a liberdade de expressão protege é o meu direito de viver e coordenar a minha própria vida: é exatamente o conteúdo do discurso que deve ser protegido, porque ele se relaciona com aquilo que é mais caro e mais pessoal por parte do falante.

\section{REFERÊNCIAS}

AARNIO, Aulis. Introduction. In: PECZENIK, Aleksander. On Law and Reason. 2. ed. Dordrecht: Springer, 2008. p. 1-12.

AFONSO DA SILVA, Virgílio. Na encruzilhada liberdade-autoridade: a tensão entre direitos fundamentais e interesses coletivos. In: ALMEIDA, Fernando Dias Menezes de. (Org.). Direito Público em evolução: estudos em homenagem à Professora Odete Medauar. Belo Horizonte: Fórum, 2013. p. 735-747.

BAKER, C. Edwin. Autonomy and Hate Speech. In: HARE, Ivan; WEINSTEIN, James. (Ed.) Extreme Speech and Democracy. Oxford: Oxford University Press, 2008. p. 139-157.

BAKER, C. Edwin. Harm, Liberty, and Free Speech. Southern California Law Review 70 (1997).

DAMER, Edward. Attacking Faulty Reasoning. 6. ed. Belmont: Wadsworth, 1998.

DWORKIN, Ronald. Taking Rights Seriously. Cambridge: Harvard University Press, 1977.

DWORKIN, Ronald. Uma questão de princípio. Tradução de Luís Carlos Borges. São Paulo: Martins Fontes, 2001.

${ }^{25}$ GEORGE, Robert P. Making Men Moral - Civil liberties and public morality. Oxford: Oxford University Press, 2002, p. 83-84.

${ }^{26}$ AFONSO DA SILVA, Virgílio. Na encruzilhada liberdade-autoridade: a tensão entre direitos fundamentais e interesses coletivos. In: ALMEIDA, Fernando Dias Menezes de. (Org.). Direito Público em evolução: estudos em homenagem à Professora Odete Medauar. Belo Horizonte: Fórum, 2013, p. 735-747 (746). 
DWORKIN, Ronald. Foreword. In: HARE, Ivan; WEINSTEIN, James. (Ed.) Extreme Speech and Democracy. Oxford: Oxford University Press, 2008. p. v-ix.

DWORKIN, Ronald. A New Map of Censorship. Index on Censorship 35 (2006). p. 130.

DWORKIN, Ronald. Uses and abuses. Index on Censorship (2002). p. 58-59.

DWORKIN, Ronald. Even bigots and Holocaust deniers must have their say: The British media were right not to publish the Danish cartoons, but that doesn't mean freedom of speech should have limits. The Guardian (14/02/2006). Disponível: http://www.theguardian.com/world/2006/feb/14/muhammadcartoons. comment.

GEORGE, Robert P. Making Men Moral - Civil liberties and public morality. Oxford: Oxford University Press, 2002.

GRIMM, Dieter. The Holocaust Denial Decision of the Federal Constitutional Court of Germany. In: HARE, Ivan; WEINSTEIN, James. (Ed.) Extreme Speech and Democracy. Oxford: Oxford University Press, 2008. p. 557-561.

KOPPELMAN, Andrew. Waldron, Responsibility-rights, and Hate Speech. 43 Arizona State Law Journal 1201 (2011).

POST, Robert. Hate Speech. In: HARE, Ivan; WEINSTEIN, James. (Ed.) Extreme Speech and Democracy. Oxford: Oxford University Press, 2008. p. 123-138.

WALDRON, Jeremy. The Harm in Hate Speech. Cambridge: Harvard University Press, 2012.

Recebido em: 14.04.2019 / Aprovado em: 07.10.2021 / Publicado em: 25.11.2021

\section{COMO FAZER REFERÊNCIA AO ARTIGO (ABNT):}

LEÃO, Martha Toribio. Liberdade de expressão e seus limites: contributo para o estudo do tema a partir de Jeremy Waldron. Revista Eletrônica do Curso de Direito da UFSM, Santa Maria, RS, v. 16, n. 1, e37763, jan/abr. 2021. ISSN 1981-3694. DOI: http://dx.doi.org/10.5902/1981369437763. Disponível em: https://periodicos.ufsm.br/revistadireito/article/view/37763. Acesso em: dia mês. ano.

Direitos autorais 2021 Revista Eletrônica do Curso de Direito da UFSM

Editores responsáveis: Rafael Santos de Oliveira e Angela Araujo da Silveira Espindola

Esta obra está licenciada com uma Licença Creative Commons Atribuição-NãoComercial-SemDerivações 4.0 Internacional.

\section{SOBRE A AUTORA}

MARTHA TORIBIO LEÃO

Professora de Direito Tributário da Faculdade de Direito da Universidade Presbiteriana Mackenzie (São Paulo/SP) e do Mestrado Profissional do Instituto Brasileiro de Direito Tributário ? IBDT. Doutora em Direito Tributário pela Universidade de São Paulo com distinção e indicação para publicação (2017), com estadias de pesquisa na Faculdade de Direito da Universidade de Coimbra, em Portugal (2016) e no Max-Planck-Institut für Steuerrecht und Öffentliche Finanzen, MAXPLANCK, na Alemanha (2017). Mestre em Direito Tributário pela Universidade de São Paulo, com dissertação indicada para publicação (2014). Mestre em Teoria do Direito e Democracia Constitucional no Istituto Tarello per la Filosofia del Diritto/Università Degli Studi di Genova (2018). Especialista em Direito do Estado (2012) e Graduada em Direito (2010) pela Universidade Federal do Rio Grande do Sul. Integrante do Conselho Deliberativo do Instituto Brasileiro de Direito Tributário IBDT. Sócia no Escritório Humberto Ávila Advocacia, em São Paulo/SP 